Int. J. Dev. Biol. 52: 1089-1098 (2008)

doi: $10.1387 / \mathrm{ijdb} .072519 \mathrm{jx}$

\title{
Apo-14 is required for digestive system organogenesis during fish embryogenesis and larval development
}

\author{
JIAN-HONG XIA, JING-XIA LIU, LI ZHOU, ZHI LI and JIAN-FANG GUI* \\ State Key Laboratory of Freshwater Ecology and Biotechnology, Institute of Hydrobiology, Chinese Academy of Sciences, \\ Graduate School of the Chinese Academy of Sciences, Wuhan, China
}

\begin{abstract}
Apo-14 is a fish-specific apolipoprotein and its biological function remains unknown. In this study, CagApo-14 was cloned from gibel carp (Carassius auratus gibelio) and its expression pattern was investigated during embryogenesis and early larval development. The CagApo-14 transcript and its protein product were firstly localized in the yolk syncytial layer at a high level during embryogenesis, and then found to be restricted to the digestive system including liver and intestine in later embryos and early larvae. Immunofluorescence staining in larvae and adults indicated that CagApo-14 protein was predominantly synthesized in and excreted from sinusoidal endothelial cells of liver tissue. Morpholino knockdown of CagApo-14 resulted in severe disruption of digestive organs including liver, intestine, pancreas and swim bladder. Moreover, yolk lipid transportation and utilization were severely affected in the CagApo-14 morphants. Overall, this data indicates that CagApo-14 is required for digestive system organogenesis during fish embryogenesis and larval development.
\end{abstract}

KEY WORDS: apolipoprotein, apo-14, digestive system, organogenesis, gibel carp

\section{Introduction}

Apolipoproteins are the protein moieties of lipoproteins, and play critical roles in lipoprotein metabolism (Paolucci et al., 1998) and in innate immune system (Concha et al., 2003). Recent studies have revealed that high-density lipoprotein (HDL) in teleostean fish corresponds to the most abounding plasma protein and is constituted by two major apolipoproteins which are 28 $\mathrm{kDa}$ apolipoprotein and $14 \mathrm{kDa}$ apolipoprotein (Kondo et al., 2001; Concha et al., 2004). The 14 kDa apolipoprotein was early identified as a major component of HDL from Japanese eel (Kondo et al., 2001), and now also identified from common carp (Concha et al., 2004), pufferfish (Kondo et al., 2005), orangespotted grouper (Zhou et al., 2005), grass carp (Chang et al., 2005) and fathead minnow (Wintz et al., 2006). In common carp, the major constituents of HDL, $28 \mathrm{kDa}$ ApoA-I and $13 \mathrm{kDa}$ ApoAII, were shown to display antimicrobial activity (Concha et al., 2003) and to be potentially important effectors of innate immunity (Concha et al., 2004). Kondo et al. (2001) characterized three main apolipoproteins Apo-28 kDa, Apo-27 kDa and Apo-14 kDa in pufferfish, and demonstrated that Apo-28 kDa and Apo-27 kDa were homologues of mammalian ApoA- I, whereas Apo-14 was a unique apolipoprotein, and specific to fish. The uniqueness sug- gested that Apo-14 might be more important than other apolipoproteins (Kondo et al., 2005), because most fish use lipids as the principal energy source in contrast to mammals which mainly use carbohydrates (Watanabe, 1982). On the other hand, the $28 \mathrm{kDa} A p o A$-/ was demonstrated to be highly expressed during embryonic development in zebrafish several years ago (Babin et al., 1997). However, little is known about expression patterns and physiological functions of the apolipoproteins during fish embryogenesis.

Gibel carp, Carassius auratus gibelio, because of its unique triploid genome and dual reproduction modes of gynogenesis and bisexuality (Gui, 1993; Zhou et al., 2000; Zhou and Gui, 2002), has been used as a promising study model for reproductive and evolutionary mechanisms (Xie et al., 2001; Dong et al., 2004; Yang and Gui, 2004; Yin et al., 2007). In order to identify some differentially expressed genes in early embryogenesis, two kinds of SMART cDNAs were respectively synthesized from the mature eggs and gastrula embryos, and the gastrula embryo SMART cDNA library was constructed. Following this program, some

\footnotetext{
Abbreviations used in this paper: MO, morpholino oligonucleotide; hpf, hours post fertilization; ORO, Oil Red O; YSL, yolk syncytial layer; aa, amino acid.
}

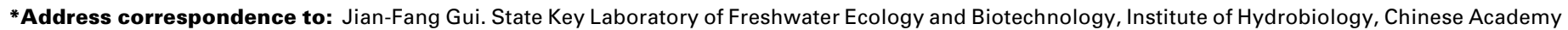
of Sciences, Graduate School of the Chinese Academy of Sciences, Wuhan 430072, China. Fax: +86-27-6878-0123. e-mail address: jfgui@ihb.ac.cn
} 
differentially expressed genes at gastrula stage were screened, and one of them was found to be Apo-14(Liu etal., 2005). The aim of this study was to characterize Carassius auratus gibelio Apo14 (CagApo-14) molecule, and to reveal its expression pattern and physiological functions during embryogenesis. We showed here that the gibel carp Apo-14 was expressed in yolk syncytial layer (YSL) of early embryos from gastrula to hatching stage, and restricted to digestive system including liver and intestine in later embryos and early larvae. To reveal the physiological functions during embryogenesis, we used the specific antisense morpholino to abrogate CagApo-14 protein during gibel carp embryogenesis. As a result, severe development abnormalities of digestive system were observed in the CagApo-14 morphants.

\section{Results}

\section{Molecular characterization and differential expression pat- tern of CagApo-14 during embryogenesis}

To reveal differentially expressed genes at gastrula embryos relative to mature eggs, about 1500 clones from the gastrula SMART cDNA library were screened with two probes prepared from gastrula first-strand cDNAs and mature egg first-strand cDNAs respectively. As shown previously (Liu et al., 2005), 130 positive clones specific to gastrula embryos were obtained, and two of them were revealed to be full length cDNA clones of CagApo-14 gene through sequencing analysis and database searches. This gene codes for a protein 141 amino acids in length (Fig. 1), with the first 19 amino acids representing a putative signal peptide by prediction with SignalP 3.0 program. It has a $48 \mathrm{bp}$ of 5'-UTR and a 283 bp 3'-UTR including a typical polyadenylation signal sequence AATAAA located $17 \mathrm{bp}$ upstream from the poly (A) tail. Glycosylation site analysis by NetNGlyc 1.0 and YinOYang 1.2 didn't find any potential N-glycosylation site or Oglycosylation site. NetPhos 2.0 analysis revealed four potential phosphorylation sites (Ser43, Ser57, Ser64, Ser74) (Fig. 1A).

Homology searches revealed five homologues from five fish species, which are grass carp (Ctenopharyngodon idella), Japanese eel (Anguilla japonica), pufferfish ( Takifugu rubripes), European flounder (Platichthys flesus) and orange-spotted grouper (Epinephelus coioides). As shown in Fig. 1B, the amino acid identity between CagApo-14 and other Apo-14 ranges from 51\%

Fig. 1. Molecular characterization and expression pattern of CagApo14 during embryogenesis. (A) Nucleotide sequence and deduced amino acid sequence of CagApo-14. The $\mathrm{N}$-terminal putative signal peptide is underlined. The asterisk indicates the stop codon and putative polyadenylation signal is bolded. Potential serine phosphorylation sites are shadowed. The nucleotide sequence has been submitted to GenBank databases under the accession number AY773183. (B) Amino acid alignment of 6 complete Apo-14 polypeptides from 6 species of fish, including gibel carp (this study), grass carp (GenBank accession no. AY445924), eel (GenBank accession no. AB046209), pufferfish (GenBank accession no. AB183288), flounder (GenBank accession no. AJ843093) and grouper (GenBank accession no. DN552074). Black boxes: identical residues, gray boxes: conservative substitutions. (C) RT-PCR detection of CagApo-14 transcript during embryogenesis. E1-mature eggs, E2fertilized eggs, E3-two cell stage, E4-multi-cell stage, E5-morula, E6blastula, E7-gastrula, E8-neurula, E9-tailbud stage, E10-hatching embryos, E11-hatched larvae. Ubiquitous expression of $\alpha$-tubulin was used as the endogenous control (C, top). (grass carp) to $39 \%$ (European flounder), being the $\mathrm{N}$-terminal region of the protein the most conserved.

RT-PCR analysis revealed differential expression pattern of CagApo-14during embryogenesis. No maternal CagApo-14transcript was found in eggs and early embryos, and the zygotic CagApo-14 transcript was firstly detected at the gastrula stage, rapidly reaching a high level at neurula stage which was maintained until hatching (Fig. 1C).

Yolk syncytial layer and digestive system-specific expression of CagApo-14 in embryos and early larvae

Expression pattern of CagApo-14 was further analyzed by whole-mount in situhybridization. As shown in Fig. 2, CagApo-14 was expressed in a dynamic fashion during embryogenesis and early larval development. No positive signals were observed in early embryos before blastula stage (data not shown). CagApo14transcript was detected at YSL of embryos from gastrula stage to hatching stage (Fig. 2A-C). At the just hatched larvae, CagApo14 transcript was restricted to primordial digestive tract (Fig. 2D),

A

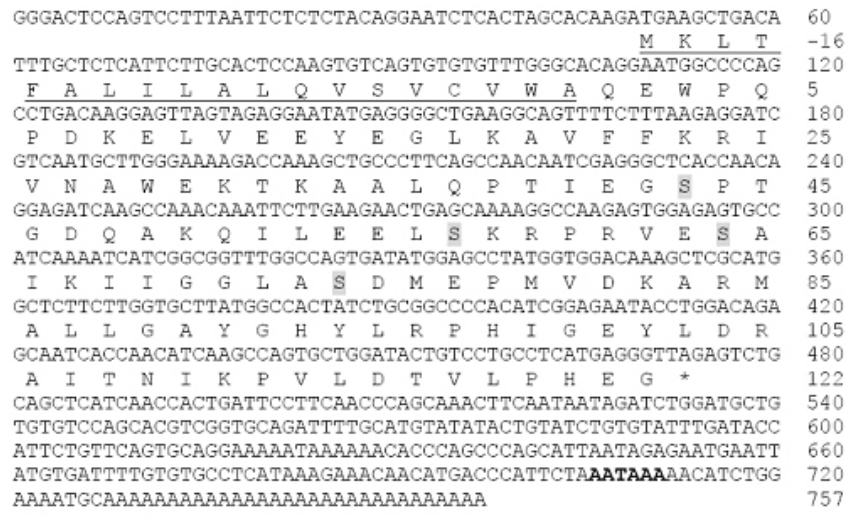

B
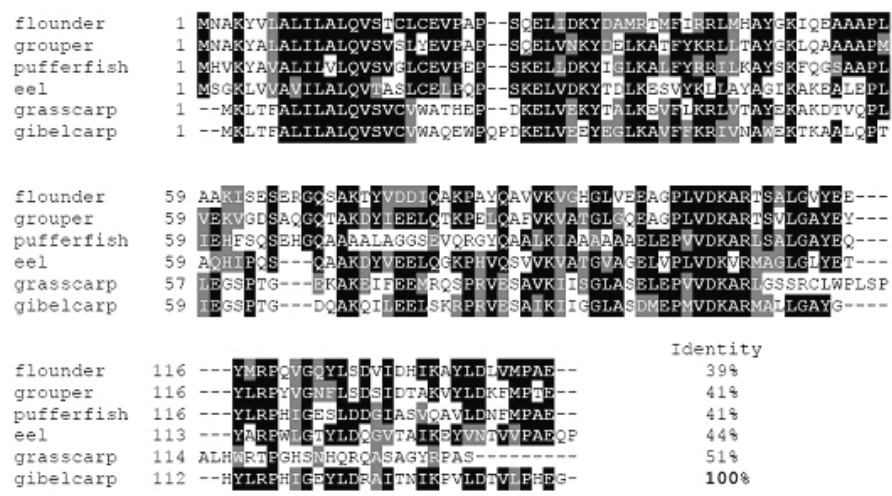

C

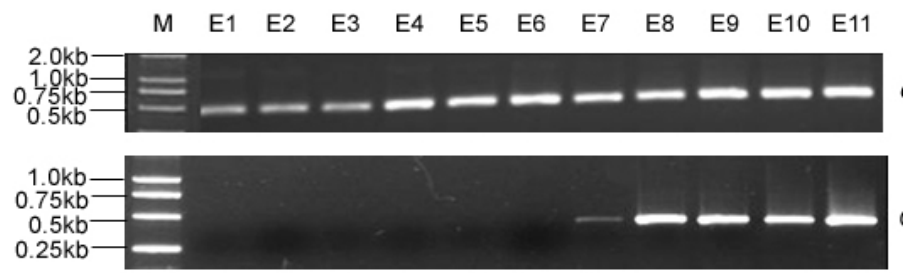


and then, high concentration of CagApo-14 transcript appeared on liver, intestinal bulb and swim bladder (Fig.2E-H) along with the larva development. Through 3-5 dpf, CagApo-14expression was specifically enriched in intestine, liver, swim bladder, and pharynx (Fig. 2I-L), especially in liver (Fig. 2L). The data suggested that CagApo-14 might be specifically expressed in YSL and digestive system during fish embryogenesis and early larval development.

\section{Liver endothelial cell expression and ubiquitous distribution of CagApo-14 protein in larvae and adults}

We also generated polyclonal antibodies against CagApo-14 from rabbit. With the polyclonal antibodies, Western blot analysis was performed on protein lysates from embryos at different developmental stages. A specific band at $14 \mathrm{kDa}$ was verified in mature eggs (Fig. 3A, lane 1), suggesting the presence of maternal storage of CagApo-14 protein. As fertilization and cleavage occurs, no maternal CagApo-14 was detected in early embryos (Fig. 3A, lane 2-7). The immunoreactive bands reappeared from neurula stage (Fig. 3A, lane 8), which should be the CagApo-14 protein translated from zygotic transcript.

To further test the specificity of anti-CagApo-14 antibodies, the antiserum was pre-adsorbed with the purified recombinant CagApo-14 protein for $16 \mathrm{~h}$ at $4{ }^{\circ} \mathrm{C}$ and set as negative control for both Western blot detection and immunofluorescence staining. Indeed, the single band at $14 \mathrm{kDa}$ could not be recognized by the pre-adsorbed antiserum (Fig. 3B), and no brilliant green immunofluorescence but only faint diffuse background was observed in the section stained by the pre-adsorbed antiserum (Fig. 3D) in comparison with Fig. 3C. Control was also done with normal rabbit serum, and no signal could be detected in Western blot analysis and immunofluorescence staining (data not shown). The data demonstrated the specificity of anti-CagApo-14 antiserum.

Then the anti-CagApo-14 antiserum was used to trace the localization and distribution of CagApo-14 protein during embryogenesis and larval development. Fig. 3E-H showed its dynamic distribution during embryogenesis. In early embryos at 5-somite stage, CagApo-14 protein was detected in YSL, and formed two continuous fluorescence rings around the whole embryo body and YSL (Fig. 3E, F). After hatching, predominant localization of CagApo-14 protein was obviously observed in the primordial digestive organs including liver and intestine bulb (Fig. 3G). In 5 day larva after hatching, the liver had expanded greatly. At that time, numerous hepatocytes with CagApo-14 immunofluorescence invaded into the yolk sac, and characteristic fingerlike intestinal villi with positive signal appeared on the intestinal bulb (Fig. 3H).

Moreover, double staining of DAPI for nucleus (blue) and green immunofluorescence for CagApo-14 further revealed predominant localization and differential distribution in developing liver. As shown in Fig. 4A-F, the CagApo-14 positive signal was predominantly seen in liver, intestinal gut and swim bladder of the 6 dph larva, but obviously differential distribution was observed in liver (Fig. 4A, E). Interestingly, a magnified observation revealed an island-like distribution (Fig. 4B, F), and the cells stained with strong immunofluorescence could be distinguished by their prolate nuclei, which were clearly different from numerous hepatocytes in the liver tissue (Fig. 4D). Obviously, CagApo-14 protein was synthesized in and excreted from these special endothelial cells, since the liver tissue is basically composed of hepatocytes

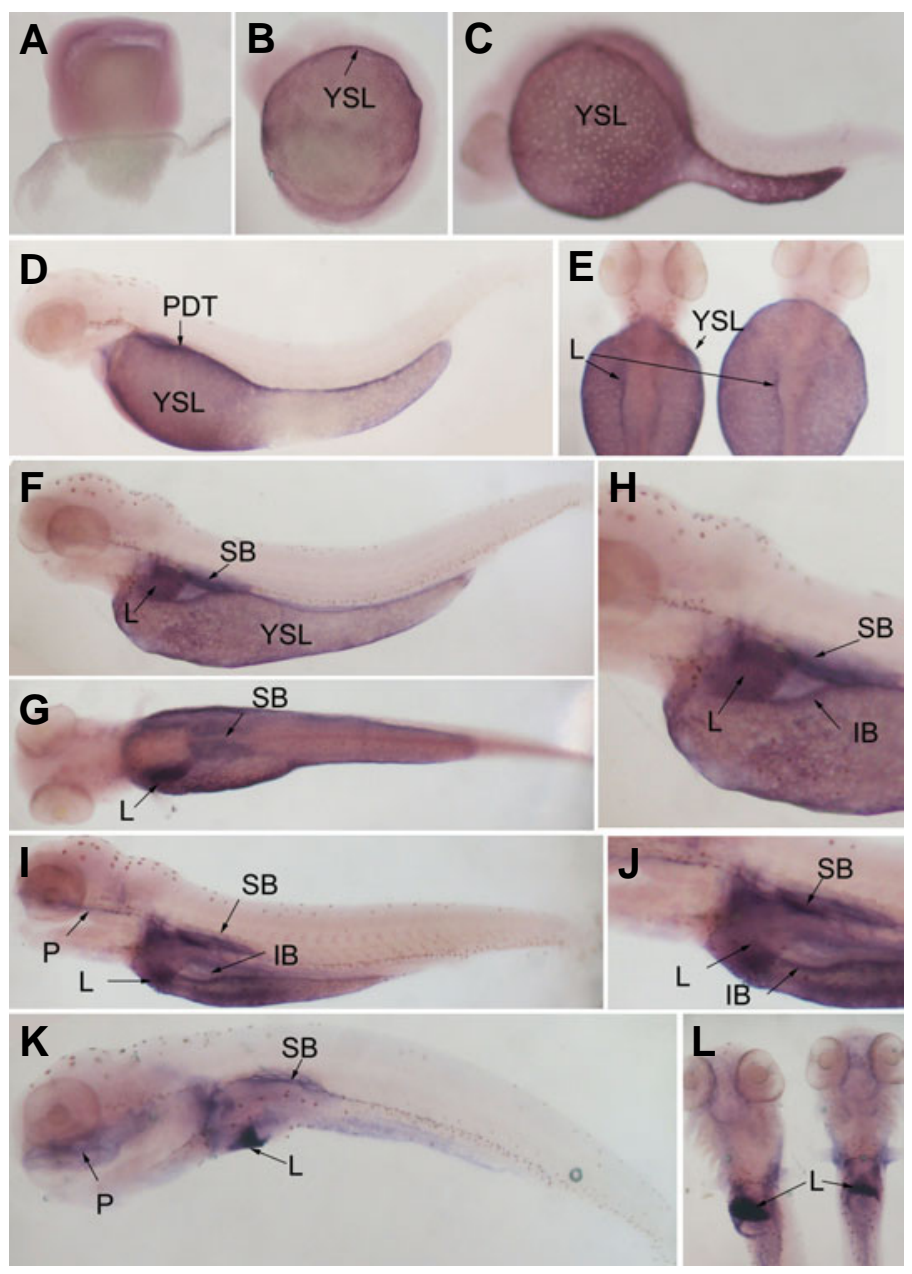

Fig. 2. Expression pattern of CagApo-14 during embryogenesis determined by whole-mount in situ hybridization. (A) Gastrula embryo (8 hpf), (B) tail bud embryo (14 hpf), (C) hatching embryo (24 hpf), (D) just hatched larva (48 hpf), (E) dorsal view of just hatched larvae, (F) lateral view of $1 \mathrm{dph}$ larva (72 hpf), (G) dorsal view of $1 \mathrm{dph}$ larva, (H) partial magnification of (F), (I) 3 dph larva, (J) partial magnification of (I), (K) 5 dph larva, (L) ventral view of 5 dph larvae. YSL, yolk syncytial layer; $P D T$, primordial digestive tract; $I B$, intestine bulb; $L$, liver; $S B$, swim bladder; $P$, pharynx; dph, days post hatching; hpf, hours post fertilization.

and invading endothelial cells (Zaret, 2002; Lee et al., 2007).

Following the above observation, we further examined the cellular distribution of CagApo-14 protein in adult liver tissue by immunofluorescence staining. As shown in Fig. 4G-L, CagApo-14 immunofluorescence was regularly distributed as dots and lines in liver section (Fig. 4G-I). Higher magnification revealed that the immunostained dots and lines were the transverse and sagittal sinusoid capillaries, respectively (Fig. 4J-L). It was consistent with the above observations in larval liver that CagApo-14 protein was localized in the liver sinusoidal endothelial cells. It is well known that the unusual sinusoid capillary is composed of a discontinuous layer of endothelial cells with large, irregular openings or fenestrations, and the basement membrane under these endothelial cells is also incomplete. Blood plasma easily percolates through the sinusoidal fenestrations and so makes intimate contact and facilitating exchange with the neighboring hepatocytes.

Tissue distribution of CagApo-14 was further examined in adult 
A
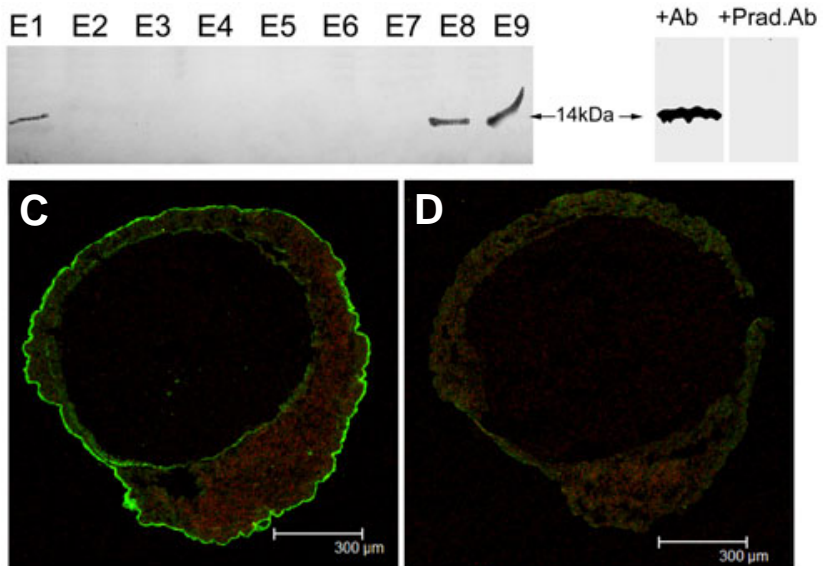

$\mathbf{E}$
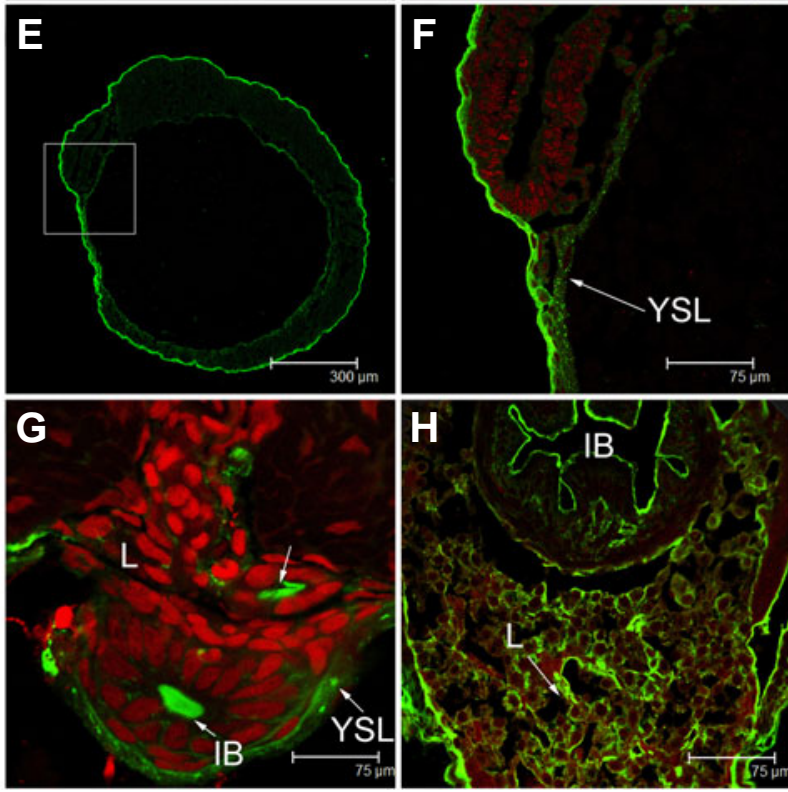

Fig. 3 (Left). Cellular localization of CagApo-14 protein during embryogenesis. (A) Western blot detection of CagApo-14 protein during embryogenesis. E1 to E9 respectively represents protein samples from mature eggs and different stage embryos. E1, mature eggs; E2, fertilized eggs; E3, two cell stage; E4, multi-cell stage; E5, morula; E6, blastula; E7, gastrula; E8, neurula; E9, tailbud stage. (B-D) Specificity of anti-CagApo14 antiserum in Western blot and immunofluorescence staining. (B) Western blot detection of egg extracts by the anti-CagApo-14 antiserum (Ab, left) and by the pre-adsorbed antiserum (Prad. Ab, right). (C) Immunofluorescence staining of 5-somite stage embryo section by the anti-CagApo-14 antiserum. (D) Control of the same 5-somite stage embryo section stained by the pre-adsorbed antiserum. (E-H) Immunofluorescence staining of CagApo-14 protein in embryo and larva sections. Green fluorescence was immunostained by anti-CagApo-14, and red fluorescence stained by PI showing the nuclear position. (E) 5-somite stage embryo. (F) Magnification of the framed area in (E). (G) Cross section through primordial intestine bulb and liver of the $1 \mathrm{dph}$ larva. (H) Cross section through intestine bulb and liver of the $5 \mathrm{dph}$ larva. YSL, yolk syncycial layer; L, liver; IB, intestine bulb.

Fig. 4 (Right). Cellular localization and distribution of CagApo-14 protein in larvae and adults. (A-F) Double staining of DAPI for nucleus (b/ue) and immunofluorescence for CagApo-14 (green) in liver tissue of 6 dph larvae. The top line (A,B) shows the immunofluorescence staining of CagApo14, middle line (C,D) shows the results stained by DAPl, and bottom line (E,F) shows the mergence of the CagApo-14 green immunofluorescence and nucleus blue fluorescence. The circles highlight special endothelial cells in the liver tissue. IB-intestinal bulb, L-liver, SB-swim bladder. (G-L) Double staining of DAPI for nucleus (blue) and immunofluorescence for CagApo-14 (green) in adult liver tissue. (J-L) are the partial magnification of (G-I). The left row $(\mathbf{G}, \mathbf{J})$ shows the immunofluorescence staining of CagApo-14, middle row $(\mathbf{H}, \mathbf{K})$ shows the results stained by DAPI, and right row $(\mathbf{I}, \mathbf{L})$ shows the mergence of the CagApo-14 green immunofluorescence and nucleus blue fluorescence. The circles highlight special endothelial cells in the liver tissue. TS-transverse sinusoid, SS-sagittal sinusoid. (M) RT-PCR detection of CagApo-14 expression in different adult tissues. Ubiquitous expression of $\alpha$-tubulin was used as the endogenous control (top). (N) Western blot detection of CagApo-14 in different adult tissues. Mr-, marker; Ib, intestine bulb; Pi, posterior intestine; Oe, oesophagus; L, liver; Sp, spleen; Ki, kidney; Mu, muscle; Ov, ovary; Br, brain; He, heart; Te, testis; Gi, gills; Sk, skin; Ph, pharynx; Se, serum.
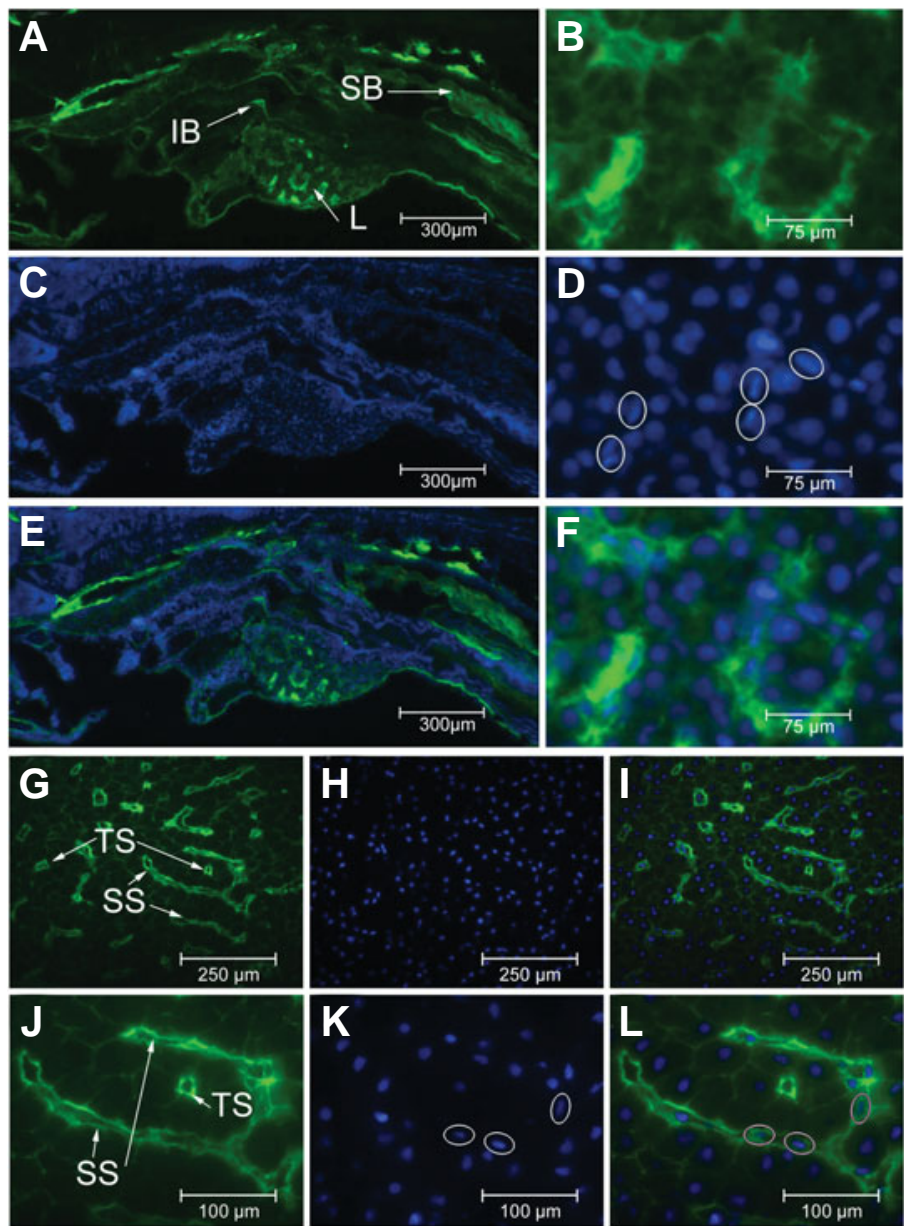

M

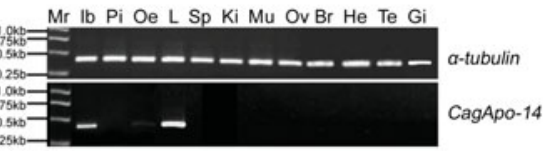

Sk Ib Ph Pi Oe Te He Br Or Mu Ki Sp L Gi Se

$14 \mathrm{kDa}$ 
fish by RT-PCR and Western blot analysis. As shown in Fig. 4M, CagApo-14 was restrictedly transcribed in liver and intestinal bulb, but CagApo-14 protein seemed to be distributed in a much more ubiquitous manner (Fig. 4N). In all of the examined tissues, including skin, intestinal bulb, pharynx, posterior intestine, oesophagus, testis, heart, brain, ovary, muscle, kidney, spleen, liver, and serum, a positive $14 \mathrm{kDa}$ band was revealed by Western blot detection, and its content was the most abundant in serum (Fig. 4N). The ubiquitous existence of CagApo14 protein was consistent with the presumed role as a lipid transporter in the bloodstream, and also indicated the existence of a ubiquitous receptor for Apo-14 in all the examined tissues. The cloning and characterization of this receptor still awaits further scrutiny.

\section{Disruption of digestive system organogenesis in CagApo- 14 morphants}

To get a better insight into its biological function during embryogenesis, we sought to abrogate CagApo-14 protein in developing gibel carp embryos using antisense morpholino oligos. A translation-blocking morpholino (MO-CagApo-14) that specifically targets to a 25 base-pair sequence around the start codon AUG was designed, and injected into fertilized eggs of gibel carp at the one-cell stage. Firstly, the optimal delivering dose was determined by injections of MO-CagApo-14 in a dilution series, that is, $1 \mathrm{mM}, 0.5 \mathrm{mM}$ and $0.3 \mathrm{mM}$. In the later experiments, $0.3 \mathrm{mM}$ was adopted as the optimal dose, since working with this dose resulted in anticipated phenotypes in most but not all of the injected embryos. No obvious off-target effects, such as early necrosis and serious developmental delay, were displayed in all the morphants. Translation blocking of CagApo-14 transcript in the morphants was detected by Western blot. As shown in Fig. 5A, the CagApo-14 protein was not detected in the morphant embryos at $16 \mathrm{hpf}, 24 \mathrm{hpf}$ and 48 hpf, whereas a specific band of about $14 \mathrm{kDa}$ was observed in the age-matched control embryos. In comparison with high concentration of CagApo-14 protein in the control larvae, a small quantity of protein was also detected in the morphant larvae at $2 \mathrm{dph}$ (72 hpf) and $3 \mathrm{dph}$ (96 hpf). The data suggested that the injection of MO-CagApo-14 did completely block the translation of CagApo-14transcript during embryogenesis, and only small quantity of CagApo-14 protein was synthesized in the later larvae, probably resulting from the gradually dilution of MO-CagApo-14 concentration in the developing larvae.

Moreover, morphological changes were inspected in detail in the CagApo-14 morphants. In comparison with control embryos, no morphological changes were seen in CagApo-14 morphants before hatching (data not shown), but obviously phenotypic differences were observed in early larvae after hatching. Significantly, the CagApo-14 morphants showed loss and disruption of all the organs of digestive system, and no swim bladder was observed. As shown in Fig. 5B-I, at 1 day after hatching, about $40 \%$ of the CagApo-14 morphants displayed severe morphological defects, such as unabsorbable yolk, kinking tail, reduced head and eyes, and pericardial edema (Fig. 5B), and they tended to death within 3 days. At 3 days after hatching, when control larvae inflated the swim bladder, and the liver underneath the swim bladder was getting apparent (Fig. 5E), both the swim bladder and the liver tissue were not observable in the rest of CagApo-14 morphants, whereas the blood circulation seemed normal (Fig. 5D), indicating that the development of vasculature was not impaired. Along with larval development and organogenesis, while the fading region of yolk absorption was occupied with developing compact tissues in control larvae at $4 \mathrm{dph}$ (Fig. 5G), the CagApo-14 morphants with mild symptom consumed some yolk, but the digestive system was strongly suffered, and no digestion organs were observed (Fig. 5F). At $6 \mathrm{dph}$, when control larvae had formed complete digestive system and ingested exoteric food (Fig. 5I), the CagApo-14 morphants had almost exhausted the yolk, and a linear thin digestive tract was evident in the enlarged and edemic body cavity (Fig. $5 \mathrm{H}$ ). Notably, many other structures in the dorsal trunk, such as macula, notochord, fin, and musculature, seemed to be grossly normal. Finally, the CagApo-14 morphants died within a week depending on the yolk nutrition.

To clarify developmental details of internal organs, the CagApo-14 morphants at $4 \mathrm{dph}$ and $6 \mathrm{dph}$ were used to perform histological analysis. As shown in Fig. 6, in comparison with normal digestion organs in control larvae (Fig. 6A-C, G-I), intestine bulb, liver and pancreas showed severe defects in the CagApo-14 morphants (Fig. 6D-F, J-L). Intestine bulb lacked normal epithelial folds, and was just composed of one layer of polarized epithelial cells without characteristic fingerlike intestinal villi (Fig. 6E, K). Liver tissue and pancreas tissue were severely reduced to a small patch of cells (Fig. 6D-F, J-L).

A

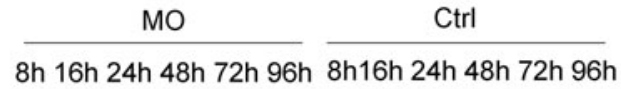

8h 16h 24h 48h 72h 96h 8h16h 24h 48h 72h 96h
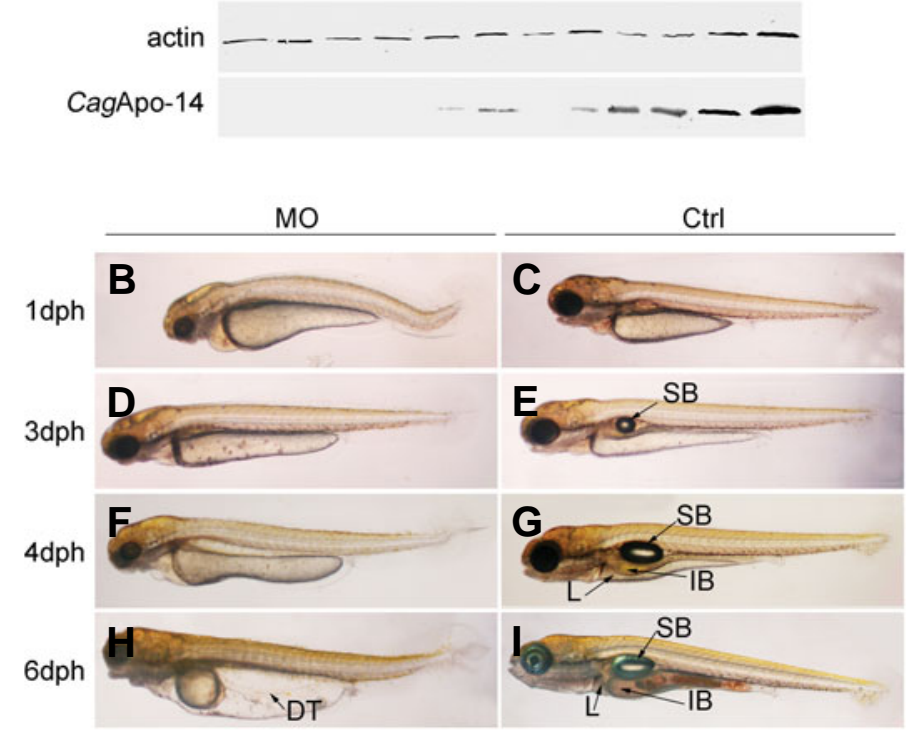

Fig. 5. CagApo-14 knockdown results in severe disruption of digestive system in morphant larvae. (A) Western bolt detection of CagApo14 in CagApo-14 morphants (MO) and control (Ctrl) experiments during embryogenesis and early larval development. Ubiquitous expression of actin was used as the endogenous control. (B-I) Representative phenotypes of CagApo-14 morphants (MO, left row) in comparison with corresponding age-matched control larvae (Ctrl, right row), at $1 \mathrm{dph}(\mathbf{B}, \mathbf{C})$, $3 d p h(\mathbf{D}, \mathbf{E}), 4 d p h(\mathbf{F}, \mathbf{G})$, and $6 d p h(\mathbf{H}, \mathbf{I})$. SB, swim bladder; L, liver; IB, intestine bulb; $D T$, digestive tract. 
$4 d$

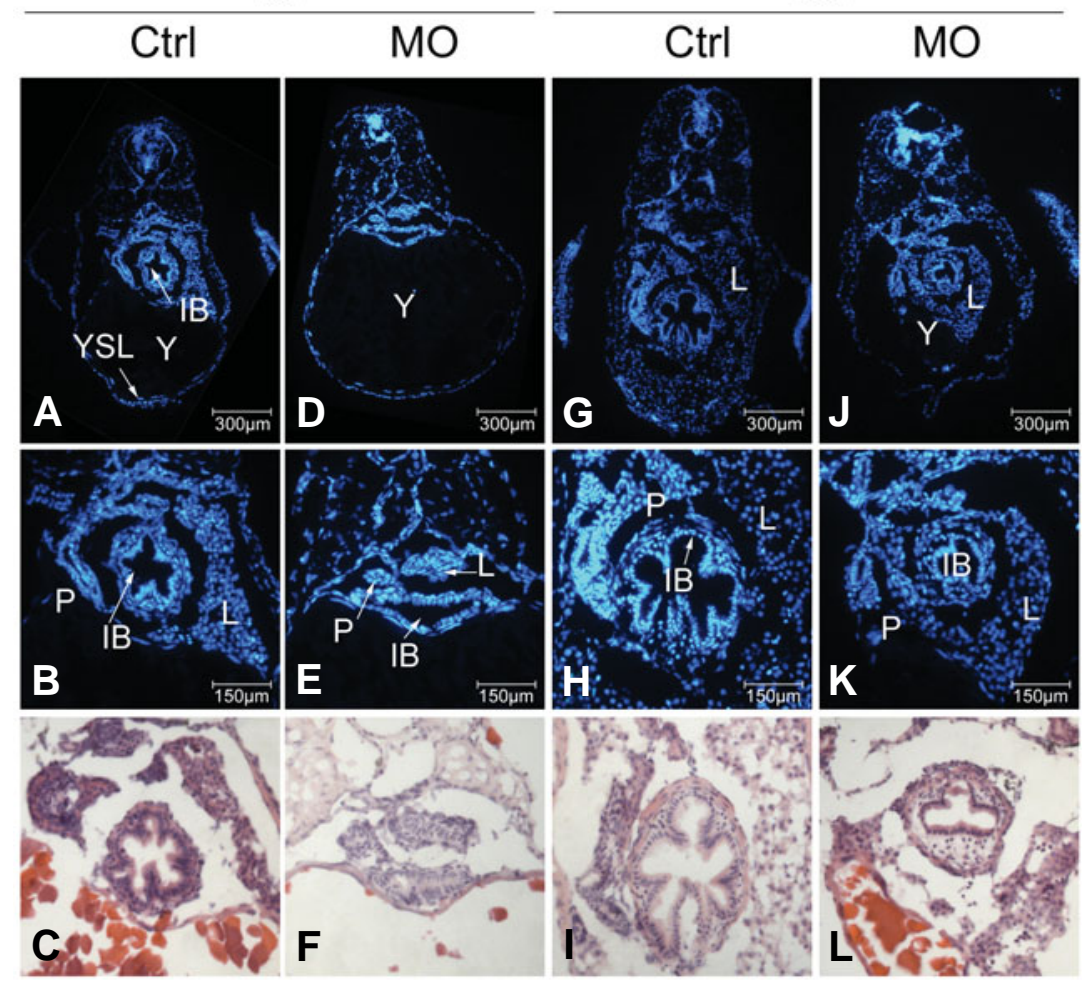

Fig. 6. Representative transverse sections through intestine bulb (IB), liver (L) and pancreas $(P)$ in control (Ctrl) and CagApo-14 morphant (MO) larvae at 4dph (A-F) and $\mathbf{6} \mathbf{d p h}(\mathbf{G}-\mathbf{L})$. The top line $(\mathbf{A}, \mathbf{D}, \mathbf{G}, \mathbf{J})$ shows the whole sections with staining of DAPI for nucleus (b/ue). The middle line $(\mathbf{B}, \mathbf{E}, \mathbf{H}, \mathbf{K})$ shows the partial magnification of top line $(A, D, G, J)$. The bottom line $(\mathbf{C}, \mathbf{F}, \mathbf{I}, \mathbf{L})$ shows the corresponding sections stained with Hematoxylin-Eosin. L, liver; $P$, pancreas; $Y$, yolk; YSL, yolk syncytial layer; IB, intestine bulb.

To confirm specificity of the MO-CagApo-14 phenotypes, we further performed rescue experiments in which we co-injected MO-CagApo-14 with a plasmid (pEGFP-N3-CagApo-14) bearing the CagApo-14 coding region under CMV promoter control. The target sequence of MO-CagApo-14 was absent in the plasmid construct. Three independent experiments were carried out in duplicate, and the data were then analyzed using paired Student's t-test. For the percentage of severely malformed embryos, the difference was statistically significant $(P<0.01)$ between the group injected with $\mathrm{MO}$ alone and the rescue group. As shown in Fig. 7, the loss and disruption of digestive system caused by MO-CagApo-14 could be rescued by the co-injection of pEGFP-N3-CagApo-14. As a further control, co-injection with pEGFP-N3 did not rescue the phenotype (Fig. 7A). A typical rescue experiment was shown in Fig. 7A. In the group injected with MO-CagApo-14 alone, only $14.0 \%$ (8/57) of embryos appeared normal, and the severely suffered embryos accounted for $40.4 \%(23 / 57)$. In the two independent experiments co-injected with two different dilutions of plasmid, the proportion of normal embryos respectively raised to $41.5 \%(27 / 65)$ and $51.3 \%(39 / 76)$. In comparison with intact digestive system of control larvae (Fig. 7B) and digestive system loss in CagApo-14morphants (Fig. 7C), the rescued larvae largely recapitulated the wild-type phenotype (Fig. 7D). At $7 \mathrm{dph}$, all of the morphants were died, but there were about $50 \%$ survivals in the rescue groups, and most of them could open their mouths and live on. These data suggested that the loss and disruption of digestive system in CagApo-14 morphants should be specifically resulted from the knockdown of CagApo-14.

\section{Defection of yolk lipid transportation in vascula- ture of CagApo-14 morphants}

To investigate whether yolk lipid transportation and utilization are affected in CagApo-14 morphants, we monitored neutral fat by staining the fixed larvae with Oil Red O (ORO) (Schlegel and Stainier, 2006). In wild-type embryos at $36 \mathrm{hpf}$, staining of yolk lipid was found in vasculature (Fig. 8A, C) and head structures (Fig. 8A), but almost no staining signal was observed in the corresponding morphants (Fig. 8B, D). At 50 hpf, even though blood circulation had become quite prosperous in both control and morphant embryos and high concentration of yolk lipid had appeared in control embryo (Fig. 8E, G), only a small quantity yolk lipid was detected in vasculature of the morphants (Fig. 8F, H).

\section{Discussion}

Apo-14, as a fish-specific apolipoprotein, has been suggested to have more significant roles than other apolipoproteins in fish (Kondo et al., 2005), but its expression pattern has been studied only in one fish species, the orange-spotted grouper (Epinephelus coioides) (Zhou et al., 2005), and its biological functions during fish embryogenesis and organogenesis remain largely unclear. In the present study, CagApo14 has been screened as a differentially expressed gene in early embryogenesis of gibel carp, and its expression patterns have been characterized in embryos and adults by RT-PCR, WISH, Western blot and immunofluorescence staining. During embryogenesis, CagApo-14gene began to transcribe from gastrula stage, and rapidly reached a high level at neurula stage. Western blot detection demonstrated the existence of maternal CagApo-14 protein in mature gibel carp eggs, and the zygotic CagApo-14 protein was detected from neurula stage. Sequentially, its expression characterization was further analyzed during the progress of embryogenesis and larval development. Interestingly, CagApo-14 was expressed in YSL of early embryos, and restricted to the digestive system including liver and intestine bulb after hatching.

An intriguing finding in this study is the association of CagApo14 with digestive system organogenesis. Knockdown of CagApo14 resulted in severe disruption of digestive organs including liver, intestine, pancreas, and swim bladder. Recently, morphogenesis and organogenesis of digestive system have been extensively investigated in zebrafish (Field et al., 2003a; Field et al., 2003b; Wallace and Pack, 2003). In the current study, we have demonstrated that the fish-specific apolipoprotein Apo-14 is an important factor required for digestive system organogenesis during fish embryogenesis and larval development (Fig. 5). We found that CagApo-14 transcript and protein product were firstly located in YSL at a very high level during embryogenesis, and then in 
A

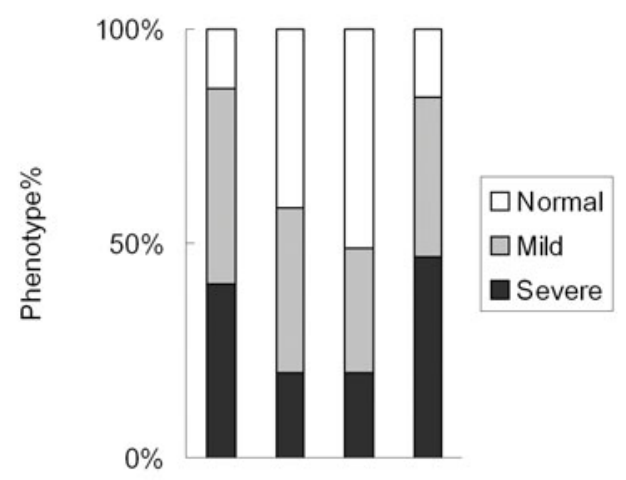

B
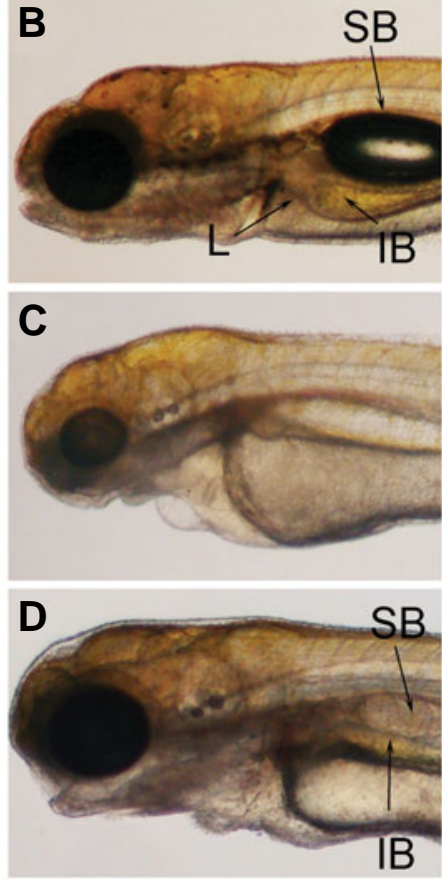

Fig. 7. Rescue experiments. (A) Percentage histogram of three phenotypes, including normal (white bar), mild (grey bar) and severe (black bar), in indicated rescue and control experiments (bottom). (B-D) Three typical phenotypes of normal (B), severe (C) and mild (D) larvae, which highlight the digestive and related organs. SB, swim bladder; IB, intestine bulb; L, liver.

digestive organs including liver and intestine after hatching (Fig. 2 and 3 ). Immunofluorescence staining in larvae and adults indicated that CagApo-14 protein was predominantly synthesized in and excreted from the sinusoidal endothelial cells of liver tissue (Fig. 4). It is well known that liver sinusoidal endothelial cells constitute unique sinusoid capillaries that differ from other capillaries in the body (Braet and Wisse, 2002; Lee et al., 2007; Straub et al., 2007), and are necessary for liver morphogenesis, even before the formation of vasculature (Matsumoto et al., 2001). The current study not only revealed predominant existence of CagApo14 in the endothelial cells (Fig. 4), but also found loss and disruption of the endothelial cells in intestine and liver of CagApo14 morphants (Fig. 6). Therefore, CagApo-14 protein might be a potential molecular marker for tracing morphogenesis and organogenesis of digestive system, especially the endothelial cells in digestive organs.

Most apolipoproteins are expressed in liver, but how the spatially-restricted expression is regulated remains unknown. It has been reported that $A p o E$ is upregulated by $B m p-2$ in mesenchymal progenitors and is highly expressed in many organs including liver and heart (Bachner et al., 1999). Bmp2 has been

Fig. 8. Yolk lipid transportation defect detected by Oil Red O (ORO) staining of the vasculature of CagApo-14 morphants. (A) Control embryo at 36 hpf. (B) CagApo-14 morphant embryo at 36 hpf. (C) Magnification of the framed area in (A). (D) Magnification of the framed area in (B). (E) Control larvae at 50 hpf. (F) CagApo-14 morphant larva at $50 \mathrm{hpf}$. (G) Magnification of the framed area in (E). (H) Magnification of the framed area in (F). ISV, intersegmental vessels; DA, dorsal aorta.

shown to play instructive role in pancreas and liver development in chick (Rossi et al., 2001) and mouse (Lemaigre and Zaret, 2004). Therefore, it would be a good idea to test whether Bmp or other signaling pathways regulate Apo-14 in fish.

Recently, molecular crosstalk between gut and the inhabited microbes has become a hot topic in vertebrates. In the absence of microbes, differentiation of gut epithelium is arrested in zebrafish (Bates et al., 2006; Cheesman and Guillemin, 2007). On the other hand, previous reports have confirmed that apolipoproteins have antibacterial activities in mammalian and fish (Srinivas et al., 1990; Singh et al., 1999), and are potentially important effectors of innate immunity in teleost fish (Concha et al., 2004). The involvement of fish Apo-14 in immune response was reported fragmentarily. In grass carp, the transcription of both Apo-14 and ApoEwas up-regulated in response to parasite infection (Chang et al., 2005). Similar up-regulation of Apo-14, Apo A-/ and Apo B was also observed in fathead minnow when exposed to the toxicant 2, 4-DNT (Wintz et al., 2006). It would be of great interest to investigate the detailed regulatory network concerning the microbes, the Apo-14 expression, and the gut development.

YSL is an embryonic structure unique to fish embryos, and has been thought to be involved in nutrient transfer from the yolk to the blastoderm (Babin et al., 1997; Poupard et al., 2000). Kudoh et al. (2001) reported a screen of gene expression patterns in zebrafish embryogenesis, and found several genes expressed in the YSL. Moreover, spatial and temporal complexity of the gene expression patterns was revealed by in situhybridization screening approach. Analogously to most of the YSL-specific genes in zebrafish embryos, CagApo-14 was expressed in the YSL and continued its expression throughout all developmental stages of embryogenesis. Furthermore, we found that the CagApo-14transcript was restricted to the digestive system in the later embryo and larval development (Fig. 2), and its protein product was observed in primordial digestive tract and related organs (Fig. 3). The anterior intestine in fish participates in lipid absorption (Bates et al., 2006) and expresses many genes involved in this process

Ctrl
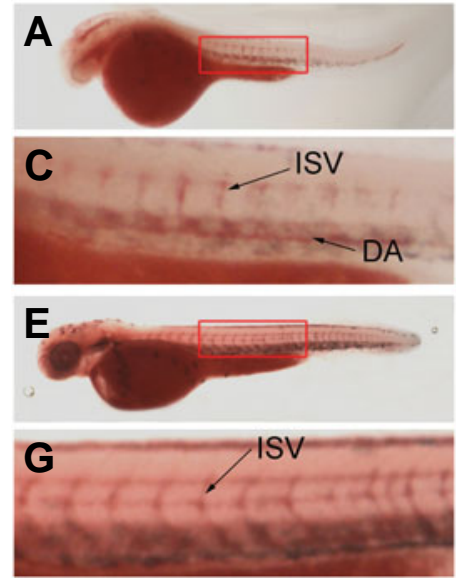

MO
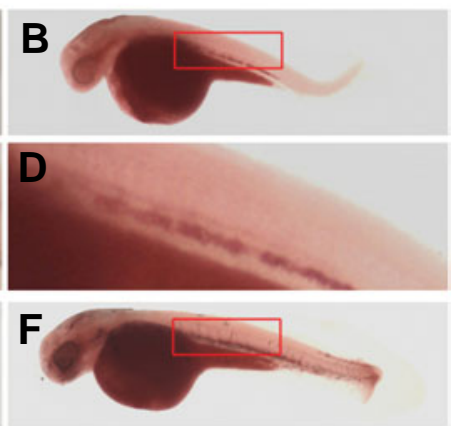

H 
such as intestinal fatty acid binding protein (i-fabp) (Andre etal., 2000). The concentrated localization of CagApo-14 transcript and its protein product is similar to that of ApoE and ApoA-I, two apolipoproteins reported previously in zebrafish (Babin et al., 1997). Both of them were considered to play important roles in the transportation of yolk nutrients to the developing embryos. Indeed, the yolk lipid transportation and utilization were demonstrated to be severely affected in the CagApo-14 morphants (Fig. 8).

This study also revealed very rapid morphological changes around the time of hatching in gibel carp, including the shrinking yolk sac, the inflating swim bladder (Fig. 5), and the rapidly developing primodia of the gills, the jaws, and the gut and its associated organs (Fig. 6). In teleostean fish, after emerging from their chorions, the larvae encounter the outside environment directly, and obtain nutrition from the environment instead of the internal yolk supply. Three coherent trophic periods have been distinguished during embryogenesis and early larval development (Poupard et al., 2000). During the endotrophic period, from fertilization to mouth opening, the endogenous yolk nutrients are the only energy source for the larvae (Kimmel et al., 1995). After mouth opening, larvae undergo a transitional endo-exotrophic period, and then the exotrophic period starts. YSL plays important roles during endotrophic period, since YSL forms a barrier between the yolk cell and the developing embryo, and as a result all nutrients from the endogenous reserves must pass through the YSL to reach the embryo and the larva. The transition from endotrophic period to exotrophic period is a major change requiring the development of organs that can digest exogenous food. The digestive organs function co-operatively not only to digest and absorb nutrient, but also to provide a barrier against environmental toxins, and have important roles in immune defense (Wallace and Pack, 2003; Stainier, 2005; Bates et al., 2006). The requirement of CagApo-14 for yolk lipid transportation and utilization suggested that CagApo14 might play significant role at endogenous trophic period and endo-exotrophic transitional period. Additionally, CagApo-14 protein was demonstrated to be ubiquitously distributed in adult fish tissues, and liver and intestinal bulb was revealed as main tissues for synthesizing CagApo-14 protein (Fig. 4M). Thus, the extensive distribution should be attributed to the transportation of blood circulation, because high concentration of CagApo-14 protein exists in the gibel carp serum (Fig. 4N).

In summary, we have characterized the fish-specific apolipoprotein CagApo-14, and revealed its expression pattern and physiological function in morphogenesis and organogenesis. We have demonstrated that CagApo-14 is required for digestive system organogenesis during fish embryogenesis and larval development. Therefore, the fish-specific Apo-14 identified in this study provides a potential marker molecule to understand morphogenesis and organogenesis of digestive system.

\section{Materials and Methods}

\section{Embryo and adult tissue collection}

Gibel carp were bred in Guanqiao Experimental Station of the Institute of Hydrobiology, Chinese Academy of Sciences. Eggs and embryos were sampled in the spawning season according to previous report (Xie et al., 2003). Different tissues were sampled from 1-year-old gibel carp cultured in the Station. Total RNAs were isolated with SV total RNA Isolation System (Promega). SMART cDNA synthesis, Iibrary construction, PCR amplification, and dot-blot hybridization were performed as described previously (Liu and Gui, 2005).

\section{Full length cDNA cloning and sequence analysis}

The positive clones containing CagApo-14 full length cDNA were screened from the gastrula SMART cDNA library as described previously (Liu et al., 2005). DNA sequencing was carried out in Bioasia sequencing company. Homology searches were performed by BLAST at web servers of USA National Center for Biotechnology Information (http://www.ncbi.nlm.nih.gov/). Homology comparison was performed using the ClustalW1.8 program. Prediction of signal peptide, glycosylation site, and phosphorylation site was done using software at the ExPASy Molecular Biology Server (http://expasy.pku.edu.cn).

\section{RT-PCR analysis}

Total RNAs were isolated by SV total RNA Isolation System (Promega) from the different tissues including brain, heart, kidney, liver, ovary, spleen, muscle, testis, oesophagus, intestinal bulb, gills and posterior intestine of 1-year-old gibel carp, and from embryos at different developmental stages including mature eggs, 5 minutes after fertilization, two cell stage, multi-cell stage, blastula, gastrula, neurula, tail bud, heartbeat, hatching and hatched larvae stage. The quality of RNA was measured by electrophoresis on $1 \%$ agarose gels. The isolated RNAs were, respectively, reverse-transcribed with M-MLV Reverse Transcriptase and oligo(dT) primer (Promega) as described by the manufacturer. The fragments representing CagApo-14 and $\alpha$ tubulin (as endogenous control) were respectively amplified by RTPCR with specific primers:

RT-F (5'-ACAAGGAGTTAGTAGAGGAA-3') and

RT-R (5'-TCTATTATTGAAGTTTGCTG-3'),

$\alpha$-tubulinF (5'-GTGCACTGGTCTTCAGGGGTT-3') and

$\alpha$-tubulinR (5'-GGGAAGTGGATGCGTGGGTAT-3'). PCR conditions were as followed: pre-denaturation at $94{ }^{\circ} \mathrm{C}$ for 3 minutes, 30 cycles of $94^{\circ} \mathrm{C}$ for $30 \mathrm{sec}, 58{ }^{\circ} \mathrm{C}$ for $30 \mathrm{sec}, 72{ }^{\circ} \mathrm{C}$ for $1 \mathrm{~min}$. Final extension at $72{ }^{\circ} \mathrm{C}$ for 5 minutes.

\section{Riboprobe synthesis and whole-mount in situ hybridization}

Embryos were fixed in $4 \%(\mathrm{w} / \mathrm{v})$ paraformaldehyde according to a previous report (Yang et al., 2001). The fragment amplified by RT-PCR was cloned to the pGEM-T vector (Promega) and linearized by Not 1 and $\mathrm{NCO}$ I, respectively. Antisense or sense digoxigenin-UTP labeled RNA probes were synthesized using T7 or Sp6 polymerase by in vitro transcription (DIG RNA labeling kit; Roche Molecular Biochemicals). The procedure of whole-mount in situ hybridization was performed as described previously (Yang et al., 2001).

\section{Fusion protein expression and antiserum preparation}

The cDNA fragment coding for CagApo-14 protein (141 aa) was subcloned into $\mathrm{pET}$-32a expression vector (Novagen). Induced with 1 $\mathrm{mM}$ isopropyl-1-thio-B-D-galactopyranoside (IPTG), a soluble Hisfusion protein of about $26 \mathrm{kDa}$ was expressed in BL21 (DE3) E. coli. To acquire the antiserum, the expressed proteins were purified with Histag purification kit (Novagene, USA) and applied to immunize white rabbit as described previously (Dong et al., 2004).

To help establish whether a particular antiserum is specific to the antigen, the pre-adsorption was carried out as follows. The optimal ration of purified $E$. coli expressed antigen to anti-CagApo-14 antiserum was determined by serial array of dilution. $0.2 \%$ diluted antiCagApo-14 antiserum was incubated with $10 \mu \mathrm{g} / \mathrm{ml}$ purified antigen at $4{ }^{\circ} \mathrm{C}$ for $16 \mathrm{~h}$ in $0.5 \%$ non-fat milk/TBST. After centrifuging the antigenantibody mixture at $16,000 \times$ g for $20 \mathrm{~min}$, the supernatant was carefully pipetted into a clean vial and used in place of the normal antiserum in 
the following Western blot detection and immunofluorescence analysis as controls.

\section{Western blot detection}

Western blot analysis was performed as described previously (Dong et al., 2004). In brief, different tissues and embryos in different developmental stages were homogenized in $1 \mathrm{ml}$ of chilled extract buffer (EB) $\left(100 \mathrm{mM} \mathrm{KCl}, 0.1 \mathrm{mM} \mathrm{CaCl}_{2}, 1 \mathrm{mM} \mathrm{MgCl}, 10 \mathrm{mM}\right.$ HEPES $\mathrm{pH} 7.7,1 \mathrm{mM}$ DTT, $0.1 \mathrm{mM}$ PMSF, $25 \mu \mathrm{g} / \mathrm{ml}$ aprotinin). Protein concentration was determined by staining with Commassie brilliant blue R-250 and measured by Eppendorf Biometer. Protein samples were electrophoresed through a $12 \%$ SDS-polyacrylamide gel, and electroblotted onto a polyvinylidene difluoride membrane using a wet electroblotter (BioRad, USA). Membranes were blocked in non-fat milk powder in Tris-buffered saline with Tween (TBST; $5 \%$ skim milk powder, $25 \mathrm{mM}$ Tris- $\mathrm{HCl}, 137 \mathrm{mM}$ $\mathrm{NaCl}, 2.7 \mathrm{mM} \mathrm{KCl}$, and $0.1 \%$ Tween 20, $\mathrm{pH} \mathrm{7.4)} \mathrm{for} 1 \mathrm{~h}$ at room temperature. After blocking, membranes were incubated with either antiCagApo-14 antiserum (1:500 dilution) or anti-actin antiserum (Santa Cruz) for control at $4{ }^{\circ} \mathrm{C}$ for $16 \mathrm{~h}$ in $1.0 \%$ non-fat milk powder/TBST solution. The membranes were washed three times for $15 \mathrm{~min}$ each in TBST buffer and incubated with 1:2000 diluted alkaline phosphatase conjugated goat anti-rabbit IgG (Vector, USA). After washing three times for 10 min each in TBST buffer, detection was performed using BCIP/NBT and scanned with an Amersham scanner (Amersham. USA).

\section{Immunofluorescence staining}

Embryos at blastula, 5-somite stage, larvae of 1 day, 4 days and 6 days after hatching, and liver tissues from one year-old adult gibel carp, were fixed with $4 \%$ paraformaldehade in PBS at $4{ }^{\circ} \mathrm{C}$ overnight. After washing with PBS ( $\mathrm{pH} 7.0)$ three times, the samples were immersed in $30 \%$ saccharose-PBS buffer overnight at $4^{\circ} \mathrm{C}$, embedded in O.C.T. (Optimal Cutting Temperature, Germany), and sectioned at $7 \mu \mathrm{m}$ in thickness with frozen microtomy (Leica). The cryostat sections were rehydrated in PBS for 30 minutes, and blocked for 1 hour with 5\% milk in PBS at room temperature to prevent non-specific binding of antibodies. The sections were then incubated with anti-CagApo-14 antibodies (1:400 dilution) for 16 hours at $4{ }^{\circ} \mathrm{C}$, washed five times with PBS (10 minutes each), subsequently incubated for 1 hour with fluorescein isothiolyanate (FITC)conjugated secondary antibody (goat anti-rabbit IgG, 1:100 dilution, Zhongshan) in the dark and washed five times with PBS (10 minutes each). After propidium iodide (PI, $5 \mu \mathrm{g} / \mathrm{ml})$ or DAPI $(1 \mu \mathrm{g} / \mathrm{ml})$ staining of nuclei for 10 minutes, the sections were washed 3 more times with PBS (10 minutes each), and finally observed with a Leica confocal laser scanning microscope.

\section{Morpholino design, plasmid construction and microinjection}

Antisense Morpholino oligonucleotide (MO) (Gene Tools LLC) was designed to target the 5'-UTR of CagApo-14 transcript. MO-CagApo-14 and standard control morpholino (Gene Tools, Philomath, OR) were dissolved in water at a concentration of $2 \mu \mathrm{M}$ and diluted to $0.3 \mu \mathrm{M}$ in $1 \times$ Danieu's buffer before injection. Morpholinos used in this study have the following sequences:

MO-CagApo-14: 5'-TGAGAGCAAATGTCAGCTT CATCTT-3'; Control MO: 5'-CCTCTTACCTCAGTTACAATTTATA-3'.

Bases in italics indicate the complement of the initiation codon for CagApo-14transcript. The ORF of CagApo-14 was amplified with 4-base mismatch forward primer

misORF-F (5'-CTCGAGATGAAACTCACTTTCGCTC-3', mismatch nucleotides leading to synonymous substitutions are underlined.) and ORF-R (5'-GGATCCACCCTCATGAGGCAGGAC-3'), and subcloned into pEGFP-N3 vector (clontech) in frame with EGFP. MOs or plasmids were injected into the yolk of 1-2 cell dechorioned embryos. 4 hours postinjection embryos were sorted, the unfertile or damaged removed and the rest allowed to grow at $24^{\circ} \mathrm{C}$ for further observation.

\section{Oil Red O staining}

Embryos and larvae were fixed in 4\% paraformaldehyde in PBS overnight at $4{ }^{\circ} \mathrm{C}$, washed in $60 \% 2$-propanol, and stained with freshly filtered $0.3 \%$ Oil Red O in 60\% 2-propanol for 2 hours (Schlombs et al., 2003).

\section{Acknowledgements}

This work was supported by the National Major Basic Research Program (grant No. 2004CB117401), the National Natural Science Foundation of China (grant No.90408013), and the Innovation Project of Chinese Academy of Sciences (grant No. KSCX2-YW-N-020).

\section{References}

ANDRE, M., ANDO, S., BALLAGNY, C., DURLIAT, M., POUPARD, G., BRIANCON, C. and BABIN, P.J. (2000). Intestinal fatty acid binding protein gene expression reveals the cephalocaudal patterning during zebrafish gut morphogenesis. Int $J$ Dev Bio/44: 249-52.

BABIN, P.J., THISSE, C., DURLIAT, M., ANDRE, M., AKIMENKO, M.A. and THISSE, B. (1997). Both apolipoprotein E and A-I genes are present in a nonmammalian vertebrate and are highly expressed during embryonic development. Proc Natl Acad Sci USA 94: 8622-7.

BACHNER, D., SCHRODER, D., BETAT, N., AHRENS, M. and GROSS, G. (1999). Apolipoprotein $\mathrm{E}$ (ApoE), a Bmp-2 (bone morphogenetic protein) upregulated gene in mesenchymal progenitors ( $\mathrm{C} 3 \mathrm{H} 10 \mathrm{~T} 1 / 2)$, is highly expressed in murine embryonic development. Biofactors 9: 11-7.

BATES, J.M., MITTGE, E., KUHLMAN, J., BADEN, K.N., CHEESMAN, S.E. and GUILLEMIN, K. (2006). Distinct signals from the microbiota promote different aspects of zebrafish gut differentiation. Dev Bio/297: 374-86.

BRAET, F. and WISSE, E. (2002). Structural and functional aspects of liver sinusoidal endothelial cell fenestrae: a review. Comp Hepato/1: 1.

CHANG, M.X., NIE, P., LIU, G.Y., SONG, Y. and GAO, Q. (2005). Identification of immune genes in grass carp Ctenopharyngodon idella in response to infection of the parasitic copepod Sinergasilus major. Parasitol Res 96: 224-9.

CHEESMAN, S.E. and GUILLEMIN, K. (2007). We know you are in there: conversing with the indigenous gut microbiota. Res Microbio/158: 2-9.

CONCHA, M.I., MOLINA, S., OYARZUN, C., VILLANUEVA, J. and AMTHAUER, R. (2003). Local expression of apolipoprotein A-I gene and a possible role for HDL in primary defence in the carp skin. Fish Shellfish Immuno/ 14: 259-73.

CONCHA, M.I., SMITH, V.J., CASTRO, K., BASTIAS, A., ROMERO, A. and AMTHAUER, R.J. (2004). Apolipoproteins A-I and A-II are potentially important effectors of innate immunity in the teleost fish Cyprinus carpio. Eur J Biochem 271: 2984-90.

DONG, C.H., YANG, S.T., YANG, Z.A., ZHANG, L. and GUI, J.F. (2004). A C-type lectin associated and translocated with cortical granules during oocyte maturation and egg fertilization in fish. Dev Bio/265: 341-54.

FIELD, H.A., DONG, P.D., BEIS, D. and STAINIER, D.Y. (2003a). Formation of the digestive system in zebrafish. II. Pancreas morphogenesis. Dev Bio/261: 197208.

FIELD, H.A., OBER, E.A., ROESER, T. and STAINIER, D.Y. (2003b). Formation of the digestive system in zebrafish. I. Liver morphogenesis. Dev Bio/253: 279-90.

GUI, J.F., LIANG, S. C., ZHU, L.F., JIANG, Y. G. (1993). Discovery of two different reproductive development modes of the eggs of artificial multiple tetraploid allogynogenetic silver crucian carp. Chin Sci Bul/38.

KIMMEL, C.B., BALLARD, W.W., KIMMEL, S.R., ULLMANN, B. and SCHILLING, T.F. (1995). Stages of embryonic development of the zebrafish. Dev Dyn 203: 253-310.

KONDO, H., KAWAZOE, I., NAKAYA, M., KIKUCHI, K., AIDA, K. and WATABE, S. (2001). The novel sequences of major plasma apolipoproteins in the eel Anguilla japonica. Biochim Biophys Acta 1531: 132-42.

KONDO, H., MORINAGA, K., MISAKI, R., NAKAYA, M. and WATABE, S. (2005). Characterization of the pufferfish Takifugu rubripes apolipoprotein multigene family. Gene 346: 257-66.

KUDOH, T., TSANG, M., HUKRIEDE, N.A., CHEN, X., DEDEKIAN, M., CLARKE, C.J., KIANG, A., SCHULTZ, S., EPSTEIN, J.A., TOYAMA, R. et al. (2001). A 
gene expression screen in zebrafish embryogenesis. Genome Res 11: 197987.

LEE, J.S., SEMELA, D., IREDALE, J. and SHAH, V.H. (2007). Sinusoidal remodeling and angiogenesis: a new function for the liver-specific pericyte? Hepatology 45: 817-25.

LEMAIGRE, F. and ZARET, K.S. (2004). Liver development update: new embryo models, cell lineage control, and morphogenesis. Curr Opin Genet Dev 14: 58290.

LIU, J.X. and GUI, J.F. (2005). Expression pattern and developmental behaviour of cellular nucleic acid-binding protein (CNBP) during folliculogenesis and oogenesis in fish. Gene 356: 181-92.

LIU, J.X., SHI, Y.H. and GUI, J.F. (2005). Screen of differentially expressed genes at gastrula stage during embryogenesis of gibel carp. Acta Hydrobiologica Sinica 29: 359-365.

MATSUMOTO, K., YOSHITOMI, H., ROSSANT, J. and ZARET, K.S. (2001). Liver Organogenesis Promoted by Endothelial Cells Prior to Vascular Function. Science 294: 559-563.

PAOlucCi, M., GuerRiero, G., BOtTe, V. and CIARCIA, G. (1998). Apolipoproteins and their electrophoretic pattern throughout the reproductive cycle in the green frog Rana esculenta. Comp Biochem Physiol B Biochem Mol Biol 119: 647-54.

POUPARD, G., ANDRE, M., DURLIAT, M., BALLAGNY, C., BOEUF, G. and BABIN, P.J. (2000). Apolipoprotein E gene expression correlates with endogenous lipid nutrition and yolk syncytial layer lipoprotein synthesis during fish development. Cell Tissue Res 300: 251-61.

ROSSI, J.M., DUNN, N.R., HOGAN, B.L.M. and ZARET, K.S. (2001). Distinct mesodermal signals, including BMPs from the septum transversum mesenchyme, are required in combination for hepatogenesis from the endoderm. Genes Dev. 15: 1998-2009.

SCHLEGEL, A. and STAINIER, D.Y.R. (2006). Microsomal Triglyceride Transfer Protein Is Required for Yolk Lipid Utilization and Absorption of Dietary Lipids in Zebrafish Larvae. Biochemistry 45: 15179-15187.

SCHLOMBS, K., WAGNER, T. and SCHEEL, J. (2003). Site-1 protease is required for cartilage development in zebrafish. Proc Nat/ Acad Sci USA 100: 14024-9.

SINGH, I.P., CHOPRA, A.K., COPPENHAVER, D.H., ANANATHARAMAIAH, G.M. and BARON, S. (1999). Lipoproteins account for part of the broad non-specific antiviral activity of human serum. Antiviral Res 42: 211-8.

SRINIVAS, R.V., BIRKEDAL, B., OWENS, R.J., ANANTHARAMAIAH, G.M., SEGREST, J.P. and COMPANS, R.W. (1990). Antiviral effects of apolipoprotein A-I and its synthetic amphipathic peptide analogs. Virology 176: 48-57.
STAINIER, D.Y. (2005). No organ left behind: tales of gut development and evolution. Science 307: 1902-4.

STRAUB, A.C., STOLZ, D.B., ROSS, M.A., HERNANDEZ-ZAVALA, A., SOUCY, N.V., KLEI, L.R. and BARCHOWSKY, A. (2007). Arsenic stimulates sinusoidal endothelial cell capillarization and vessel remodeling in mouse liver. Hepatology 45: 205-12.

WALLACE, K.N. and PACK, M. (2003). Unique and conserved aspects of gut development in zebrafish. Dev Bio/255: 12-29.

WATANABE, T. (1982). Lipid nutrition in fish. Comp Biochem Physiol B Biochem Mol Biol73: 3-15.

WINTZ, H., YOO, L.J., LOGUINOV, A., WU, Y.Y., STEEVENS, J.A., HOLLAND, R.D., BEGER, R.D., PERKINS, E.J., HUGHES, O. and VULPE, C.D. (2006). Gene expression profiles in fathead minnow exposed to 2,4-DNT: correlation with toxicity in mammals. Toxico/ Sci94: 71-82.

XIE, J., WEN, J.J., CHEN, B. and GUI, J.F. (2001). Differential gene expression in fully-grown oocytes between gynogenetic and gonochoristic crucian carps. Gene 271: 109-16.

XIE, J., WEN, J.J., YANG, Z.A., WANG, H.Y. and GUI, J.F. (2003). Cyclin A2 is differentially expressed during oocyte maturation between gynogenetic silver crucian carp and gonochoristic color crucian carp. J Exp Zoolog A Comp Exp Biol295: 1-16.

YANG, L. and GUI, J.F. (2004). Positive selection on multiple antique allelic lineages of transferrin in the polyploid Carassius auratus. Mol Biol Evol21: 1264-77.

YANG, Z., LIU, N. and LIN, S. (2001). A zebrafish forebrain-specific zinc finger gene can induce ectopic dlx2 and dlx6 expression. Dev Bio/231: 138-48.

YIN, J., XIA, J.H., DU, X. Z., LIU, J., ZHOU, L., HONG, Y.H. and GUI, J.F. (2007). Developmental expression of CagMdkb during gibel carp embryogenesis. Int J Dev Bio/51: 761-69.

ZARET, K.S. (2002). Regulatory phases of early liver development: paradigms of organogenesis. Nat Rev Genet 3: 499-512.

ZHOU, L. and GUI, J.F. (2002). Karyotypic diversity in polyploid gibel carp, Carassius auratus gibelio Bloch. Genetica 115: 223-32.

ZHOU, L., WANG, Y. and GUI, J.F. (2000). Genetic evidence for gonochoristic reproduction in gynogenetic silver crucian carp (Carassius auratus gibelio bloch) as revealed by RAPD assays. J Mol Evo/51: 498-506.

ZHOU, L., WANG, Y., YAO, B., LI, C.J., JI, G.D. and GUI, J.F. (2005). Molecular cloning and expression pattern of $14 \mathrm{kDa}$ apolipoprotein in orange-spotted grouper, Epinephelus coioides. Comp Biochem Physiol B Biochem Mol Biol 142: 432-7. 


\section{Further Related Reading, published previously in the Int. J. Dev. Biol.}

See our recent Special Issue Fertilization, in honor of David L. Garbers and edited by Paul M. Wassarman and Victor D. Vacquier at: http://www.ijdb.ehu.es/web/contents.php?vol=52\&issue=5-6

See our recent Special Issue Ear Development edited by Fernando Giraldez and Bernd Fritzsch at: http://www.ijdb.ehu.es/web/contents.php?vol=51\&issue=6-7

Developmental expression of CagMdkb during gibel carp embryogenesis Jun Yin, Jian-Hong Xia, Xin-Zheng Du, Jun Liu, Li Zhou, Yun-Han Hong and Jian-Fang Gui Int. J. Dev. Biol. (2007) 51: 761-769

Thyroid hormone receptor expression in the obligatory paedomorphic salamander Necturus maculosus Virginie Vlaeminck-Guillem, Rachid Safi, Philippe Guillem, Emmanuelle Leteurtre, Martine Duterque-Coquillaud and Vincent Laudet

Int. J. Dev. Biol. (2006) 50: 553-560

Generation of the germ layers along the animal-vegetal axis in Xenopus laevis.

$\mathrm{H}$ Yasuo and $\mathrm{P}$ Lemaire

Int. J. Dev. Biol. (2001) 45: 229-235

Blastomeres and cells with mesendodermal fates of carp embryos express cth1, a member of the TIS11 family of primary response genes.

C J Stevens, H Schipper, J Samallo, H W Stroband and T te Kronnie

Int. J. Dev. Biol. (1998) 42: 181-188

Characterization of antigens specific for spermatozoa and germ cells during early gonadal development of carp (Cyprinus carpio, Cyprinidae, Teleostei) with monoclonal antibodies.

L P Timmermans, J Wang, N Taverne, H Schipper and H K Parmentier

Int. J. Dev. Biol. (1996) 40: S221-S222

Expression of Hoxb-3 in carp (Cyprinus carpio) embryos.

P In der Rieden, C Stevens, J Samallo, H Schipper, G Te Kronnie and H W Stroband Int. J. Dev. Biol. (1996) 40: S97-S98

Embryonic expression of carp-Ovx1.

H W Stroband, C Stevens, G Te Kronnie, J Samallo and H Schipper Int. J. Dev. Biol. (1996) 40: S95-S96

Expression of Hoxb-1 during gastrulation and segmentation stages of carp (Cyprinus carpio).

C J Stevens, J Samallo, H Schipper, H W Stroband and G te Kronnie

Int. J. Dev. Biol. (1996) 40: 463-470

Transdifferentiation of pigmented multipotent epithelium during morphallactic development of budding tunicates.

K Kawamura and S Fujiwara

Int. J. Dev. Biol. (1994) 38: 369-377

Differentiation of eosinophilic granulocytes of carp (Cyprinus carpio L.).

N Kralj-Klobucar

Int. J. Dev. Biol. (1991) 35: 341-344

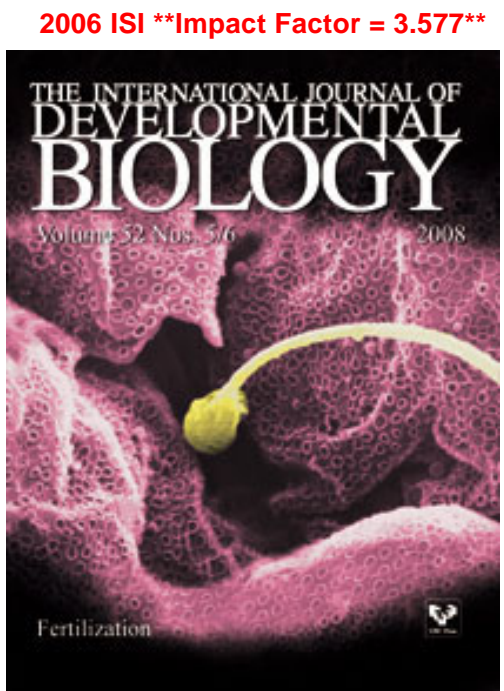

